\title{
THE MANIFESTATION OF GENOTYPES RESPONSIBLE FOR BLOOD PRESSURE AND BLOOD SUGAR LEVEL
}

\author{
Sadanobu Miyao, M.D., Goro Mimura, M.D* \\ TOMIO JinNouchi, M.D.,* AND TOSHIYUKI FuRUSHO, M.D***
}

\begin{abstract}
It has been known for a long time that hypertension and diabetes mellitus are often complicated by each other. The aim of this paper was to disclose possible causes of such complications by investigating 1) whether or not hypertension and diabetes mellitus are entirely two independent diseases, 2) whether or not they occur together only by chance, 3 ) whether or not there are some causal factors which are shared by these two diseases and 4) whether or not these two diseases occur together with some probability.

The genetic analyses of these two diseases were carried out on the basis of the genetic analyses on blood pressures (BP) and blood sugar levels (BS) in the present studies.

It was proved that the genotypic correlation coefficients of BP and BS ranged from 0.075 to 0.573 with a mean value of 0.337 and their environmental correlation coefficients were from -0.029 to -0.337 with a mean value of -0.164 . These results suggest that 1 ) the respective polygenic systems responsible for BP (hypertension) and BS (diabetes mellitus) have multiple effects and 2) the environmental factors responsible for BP and BS have inverse effects.

The negative values of the environmental correlation coefficients between $\mathrm{BP}$ and BS indicate that the environmental factors which lower BP may elevate $\mathrm{BS}$, and vice versa. An induction of an abnormal glucose tolerance as one of the side effects of thiazides, the most widely used anti-hypertensive diuretics, coincides with the inverse environmental correlation between BP and BS. This finding may be of great importance in the field of clinical genetics.
\end{abstract}

T $\mathrm{T}$ has been well noticed in the field of geriatric medicine that two major adult diseases, hypertension and diabetes mellitus, often complicate each other. Reviewing several Japanese articles, Mimura, 1,2 one of the present authors, has reported that the incidence of diabetics

\section{Key Words:}

Hypertension

Diabetes mellitus

Blood pressure

Blood sugar level

Genotypes among hypertensive patients was $2.1 \%$ to $35.8 \%$ with a mean value of $14.3 \%$ and that of hypertensive patients among diabetics was $27.0 \%$ to $48.4 \%$ with a mean value of $36.7 \%$. On the basis of these relatively high incidences of these complications, the possibility of the existence of some genetic correlations between these two diseases has been suggested.

In order to elucidate the existence of some genetic relationships between hypertension and diabetes mellitus, some genetic population analyses of blood pressures (BP) and blood sugar levels (BS) were carried out in this report.

(Received June 16, 1981; accepted May 24, 1982)

Professor Emeritus of Kumamoto University, Kumamoto Japan; *The Second Department of Internal Medicine, Ryukyu University, Naha; ${ }^{* *}$ Central Laboratory and Internal Medicine, Kurume University, Kurume; ${ }^{* *}$ The Department of Hygiene, Kagoshima University, Kagoshima, Japan

Address for correspondence: Sadanobu Miyao, M.D., 5-5-27 Toroku, Kumamoto 862, Japan 


\section{MATERIALS AND METHODS}

\section{Materials}

Twenty-four hundred and thirty-two inhabitants in 534 families in Uto and Tomiai districts near Kumamoto City were the subjects for a medical survey in 1963. There were 1,202 males and 1,230 females, aged 20 to 70 .

These individuals who were thought to suffer from nephropathia were excluded from the present studies after consulting their clinical history and the degree of albuminuria. Blood pressures $(\mathrm{mmHg})$ were examined by a Riva-Rocci sphygmomanometer in a sitting position. Blood sugar levels $(\mathrm{mg} / 100 \mathrm{ml})$ were determined using an autoanalyzer (Technicon Instrument Corporation, Model 23A) with capillary blood taken from an earlobe.

Blood pressures were expressed as systolic pressure (systolic BP) and diastolic pressure (diastolic BP), and blood sugar levels as fasting blood sugar level (fasting BS) and blood sugar level at 2 hours after meals ( $2 \mathrm{hr} \mathrm{BS}$ ).

\section{Methods of Genetic Analyses}

The individuals were classified into either 22 sex-age groups, 4 family groups (the father, the mother, the son and the daughter groups), or 2 parent-child groups (the father-son and the mother-daughter groups).

As the first step of the data analyses, the mean value (M), the standard deviation $(\sigma)$, and the distribution range of systolic $\mathrm{BP}$, diastolic $\mathrm{BP}$, fasting BS and $2 \mathrm{hr}$ BS were calculated in each sex-age group.

As the second step of the data analyses, a coordinate transformation was performed on individual's actual values of the quantitative characters $(i, j)$ in order to eliminate essential errors, which will be discussed later in this report. The following equation was employed:

$$
A_{\iota}=\left(m_{\iota}-M_{\iota}\right) / \sigma_{\iota}
$$

where $\mathrm{A}_{l}$ : the co-ordinate transformed value of an $\iota$-year-old individual,

$m_{\iota}$ : the actual value of an $\iota$-year-old individual,

$\mathrm{M}_{L}$ : the mean value of an $\iota$-year old group,

$\sigma_{\ell}$ : the standard deviation of the mean value of an t-year-old group.

As the final step of the data analyses, the individual correlation ( $r$ ) of pairs of the two quantitative characters $(i, j)$ such as systolic BPdiastolic BP and systolic BP-fasting BS, etc. was determined in 4 family groups, and then the parent-child correlation $\left(\mathrm{r}_{\mathrm{F}} \cdot \mathrm{S}, \mathrm{r}_{\mathrm{M}} \cdot \mathrm{D}\right)$ of pairs of the two quantitative characters was also determined in 2 parent-child groups.

The heritability $\left(\mathrm{h}^{2}\right)$ of each quantitative character observed in the present studies was estimated in 2 parent-child groups according to the following equation:

$$
\mathrm{h}^{2}=2 \mathrm{r}_{\mathrm{PO}}
$$

where $h^{2}$ : the heritability value,

$\mathrm{r}_{\mathrm{PO}}$ : the correlation coefficient value of the two quantitative characters in a parent-child group $\left(\mathrm{r}_{\mathrm{F} \cdot \mathrm{S}}\right.$ or $\left.\mathrm{r}_{\mathrm{M} \cdot \mathrm{D}}\right)$.

Furthermore, the phenotypic ( $\left.\mathrm{r}_{\mathrm{P} i j}\right)$, the genotypic $\left(\mathrm{r}_{\mathrm{G} i j}\right)$, and the environmental $\left(\mathrm{r}_{\mathrm{E} i j}\right)$ correlations were estimated accoridng to the following equations by using the values of such as rpo and $\mathrm{h}^{2}$, etc.:

$$
\begin{aligned}
& \mathrm{r}_{\mathrm{P} i j}=\sqrt{\mathrm{r}_{\mathrm{P} i \mathrm{P} j} \cdot \mathrm{r}_{\mathrm{O} i \mathrm{O} j}} \\
& \mathrm{r}_{\mathrm{G} i j}=\sqrt{\frac{\mathrm{r}_{\mathrm{P} i \mathrm{O} j} \cdot \mathrm{r}_{\mathrm{P} j \mathrm{O} i}}{\mathrm{r}_{\mathrm{P} i \mathrm{O} i} \cdot \mathrm{r}_{\mathrm{P} j \mathrm{O} i}}} \\
& \mathrm{r}_{\mathrm{E} i j}=\frac{\mathrm{r}_{\mathrm{P} i j}-\mathrm{r}_{\mathrm{G} i j \mathrm{~h} i \mathrm{~h} j}}{\sqrt{\left(1-\mathrm{h}_{i}{ }^{2}\right) \cdot\left(1-\mathrm{h}_{j}{ }^{2}\right)}}
\end{aligned}
$$

Estimation of the Complication Frequency of Hypertension and Diabetes Mellitus on the Data Published Elsewhere

The data quoted in this estimation was the age-dependent incidence of hypertensive patients among diabetics reported by Mimura, 2,3 and the incidences of hypertensive patients or diabetics in randomly selected populations by the Japanese Ministry of Health and Welfare, ${ }^{4}$ Mimura $^{3}$ and Kobayashi ${ }^{5,6}$ (Tables I, II and III).

The complication frequency of hypertension and diabetes mellitus was estimated according to the following equation:

$$
\Delta=\mathrm{XY}-\mathrm{x} \cdot \mathrm{y}
$$

where $\Delta:$ the value of the complication frequency of hypertension and diabetes mellitus,

$X Y$ : the age-dependent incidence of hypertensive patients among diabetics, 
TABLE I INCIDENCE OF HYPERTENSIVE PATIENTS AMONG DIABETICS

\begin{tabular}{|c|c|c|c|}
\hline \multicolumn{2}{|c|}{ Data $I^{\mathrm{a})}$} & \multicolumn{2}{|c|}{ Data $\left.I I^{\mathrm{b}}\right)$} \\
\hline Age group (years) & $\%$ & Age group (years) & $\%$ \\
\hline-40 & 29.6 & -30 & 10 \\
\hline $41-60$ & 38.6 & $31-50$ & 29 \\
\hline $61-$ & 62.0 & $51-$ & 59 \\
\hline
\end{tabular}

a) Data by Mimura(1971) 1,2 b) Data by Mimura $(1974)^{3}$

TABLE II FREQUENCY OF SYSTOLIC BLOOD PRESSURE BY AGE AND SEX

\begin{tabular}{|c|c|c|c|c|c|c|}
\hline \multirow{3}{*}{$\begin{array}{c}\text { Systolic } \\
\text { Blood } \\
\text { Pressure } \\
\text { (mmHg) }\end{array}$} & \multicolumn{6}{|c|}{ Age group (years) } \\
\hline & \multicolumn{3}{|c|}{ Male } & \multicolumn{3}{|c|}{ Female } \\
\hline & $30-39$ & $40-49$ & $50-59$ & $30-39$ & $40-49$ & $50-59$ \\
\hline-79 & & & & 0.0005 & & \\
\hline $80-89$ & 0.0010 & & 0.0010 & 0.0035 & 0.0025 & 0.0005 \\
\hline $90-99$ & 0.0120 & 0.0110 & 0.0075 & 0.0336 & 0.0170 & 0.0105 \\
\hline $100-109$ & 0.0695 & 0.0495 & 0.0310 & 0.1355 & 0.0815 & 0.0455 \\
\hline $110-119$ & 0.1890 & 0.1480 & 0.0980 & 0.2845 & 0.1730 & 0.1035 \\
\hline $120-129$ & 0.2955 & 0.2075 & 0.1350 & 0.2645 & 0.2305 & 0.1410 \\
\hline $130-139$ & 0.2160 & 0.2220 & 0.1870 & 0.1515 & 0.1905 & 0.1660 \\
\hline $140-149$ & 0.1125 & 0.1590 & 0.1810 & 0.0740 & 0.1210 & 0.1715 \\
\hline $150-159$ & 0.0545 & 0.0795 & 0.1415 & 0.0255 & 0.0735 & 0.1215 \\
\hline $160-169$ & 0.0325 & 0.0550 & 0.0870 & 0.0110 & 0.0420 & 0.0875 \\
\hline $170-179$ & 0.0105 & 0.0290 & 0.0555 & 0.0070 & 0.0325 & 0.0685 \\
\hline $180-189$ & 0.0040 & 0.0200 & 0.0325 & 0.0035 & 0.0155 & 0.0355 \\
\hline $190-199$ & 0.0015 & 0.0125 & 0.0210 & 0.0030 & 0.0085 & 0.0200 \\
\hline $200-209$ & 0.0005 & 0.0040 & 0.0120 & 0.0015 & 0.0055 & 0.0120 \\
\hline $210-219$ & 0.0005 & 0.0015 & 0.0065 & 0.0005 & 0.0040 & 0.0085 \\
\hline $220-229$ & 0.0005 & 0.0010 & 0.0035 & 0.0005 & 0.0020 & 0.0040 \\
\hline $230-239$ & 0.0005 & 0.0005 & 0.0015 & & 0.0010 & 0.0020 \\
\hline $240-249$ & & & 0.0005 & & & 0.0015 \\
\hline $250-259$ & & & & & & 0.0015 \\
\hline $260-$ & & & & & & 0.0005 \\
\hline \multirow{2}{*}{150 and over } & \multicolumn{2}{|c|}{0.1540} & & \multicolumn{2}{|c|}{0.1185} & \\
\hline & & \multicolumn{2}{|c|}{0.2823} & & \multicolumn{2}{|c|}{0.2738} \\
\hline
\end{tabular}

From data published by the Japanese Ministry of Health and Welfare (1970) ${ }^{4}$

$\mathrm{x}$ : the incidence of hypertensive patients in a sex-age group of the randomly selected population,

$y: \quad$ the incidence of diabetics in a sex-age group of the randomly selected population.

\section{RESULTS}

The mean values (M), the standard deviation $(\sigma)$, and the distribution ranges of systolic BP, diastolic BP, fasting BS and $2 \mathrm{hr}$ BS are shown in Table IV. As seen in the distribution ranges in Table IV, each minimal value did not vary greatly and had no age-dependent tendency, 


\begin{tabular}{cccc}
\hline \hline $\begin{array}{c}\text { Age group } \\
\text { (years) }\end{array}$ & Male & Female & Total \\
\hline $6-9$ & $0 / 126=0$ & $0 / 100=0$ & $0 / 226=0$ \\
$10-19$ & $2 / 252=0.0079$ & $1 / 302=0.0033$ & $3 / 554=0.0054$ \\
$20-29$ & $2 / 88=0.0227$ & $0 / 173=0$ & $2 / 261=0.0077$ \\
$30-39$ & $5 / 134=0.0373$ & $1 / 226=0.0044$ & $6 / 360=0.0167$ \\
$40-49$ & $2 / 121=0.0165$ & $9 / 182=0.0495$ & $11 / 303=0.0363$ \\
$50-59$ & $6 / 122=0.0492$ & $9 / 155=0.0581$ & $15 / 277=0.0542$ \\
$60-69$ & $6 / 98=0.0612$ & $6 / 110=0.0545$ & $12 / 208=0.0577$ \\
$70-$ & $4 / 58=0.0690$ & $4 / 48=0.0833$ & $8 / 106=0.0755$ \\
\hline Total & $27 / 999=0.0270$ & $30 / 1296=0.0231$ & $57 / 2295=0.0248$ \\
\hline
\end{tabular}

Data $\left.I I^{b}\right)$

\begin{tabular}{|c|c|c|c|c|c|}
\hline \multirow{2}{*}{$\begin{array}{l}\text { Age group } \\
\text { (years) }\end{array}$} & \multicolumn{4}{|c|}{ Year $1957-1958$} & \multirow{2}{*}{$\frac{\text { Year } 1962}{\text { Male }}$} \\
\hline & \multicolumn{2}{|r|}{ Male } & Female & Total & \\
\hline $10-19$ & $0 /$ & $0=0$ & $0 / 32=0$ & $01.32=0$ & \\
\hline $20-29$ & $0 /$ & $17=0$ & $0 / \quad 83=0$ & $01100=0$ & \\
\hline $30-39$ & $5 /$ & $456=0.0110$ & $1 / 141=0.0071$ & $6 / \quad 597=0.0101$ & $3 / 102=0.0294$ \\
\hline $40-49$ & 2631 & $7990=0.0329$ & $32 / 1636=0.0196$ & $29519626=0.0306$ & $103 / 1805=0.0571$ \\
\hline $50-59$ & 2261 & $4130=0.0547$ & $46 / 1298=0.0354$ & $272 / 5428=0.0501$ & $108 / 1230=0.0878$ \\
\hline $60-69$ & 791 & $897=0.0881$ & $35 / 812=0.0431$ & $114 / 1709=0.0667$ & $16 / 136=0.1176$ \\
\hline $70-$ & 331 & $348=0.0948$ & $29 / 531=0.0546$ & $621 \quad 879=0.0705$ & \\
\hline Unknown & 11 & $20=0.0500$ & $0 / \quad 1=0$ & $21=0.0476$ & \\
\hline Total & $607 / 1$ & $3858=0.0438$ & $143 / 4534=0.0315$ & $750 / 18392=0.0408$ & $230 / 3272=0.0703$ \\
\hline
\end{tabular}

a) Data by Mimura $(1974)^{3}$, b) Data by Kobayashi $(1959,1964)^{5,6}$

while each maximal value increased as the age of the group increased.

The correlation coefficients of two quantitative characters such as a pair of systolic BP diastolic BP or systolic BP - fasting BS, etc. in each family group are shown in Table V. The statistically significant values of correlation coefficients were obtained in pairs of systolic BP - diastolic BP and fasting BS - 2hr BS in every family groups. Some pairs of BP - BS were proved to have the statistically significant values of correlation coefficients in some family groups.

The correlation coefficien ts of two quantitative characters such as a pair of systolic BP - systolic BP or systolic BP - diastolic BP, etc. in each parent-child group are shown in Table VI.

The heritabilities of systolic BP, diastolic BP, fasting BS and $2 \mathrm{hr}$ BS in each parent-child group are shown in Table VII. The phenotypic, the genotypic, and the environmental correlation coefficients of two quantitative characters such as a pair of systolic BP - diastolic BP or systolic BP - fasting BS, etc. in each parent-child group are shown in Table VIII. It was noticed that the statistically significant high values of the phenotypic and the genotypic correlation coefficients were obtained in each parent-child group for the two pairs of the quantitative characters, namely systolic BP - diastolic BP and fasting BS $-2 \mathrm{hr}$ BS; most of the genotypic correlations between $\mathrm{BP}$ and BS were statistically significant in each parent-child group; the statistically significant negative low values of the environmental correlation coefficients were obtained for most pairs of $\mathrm{BP}$ and BS.

The estimation of the complication frequencies of hypertension and diabetes mellitus in randomly selected populations are shown in Table IX. The values of the complication frequencies were all positive and the $\Delta / \mathrm{x} \cdot \mathrm{y}$ gave the exceedingly high values from 20.000 to 82.86 with a mean value of 46.86 . 
Manifestation of Genotypes Responsible for BP and BS

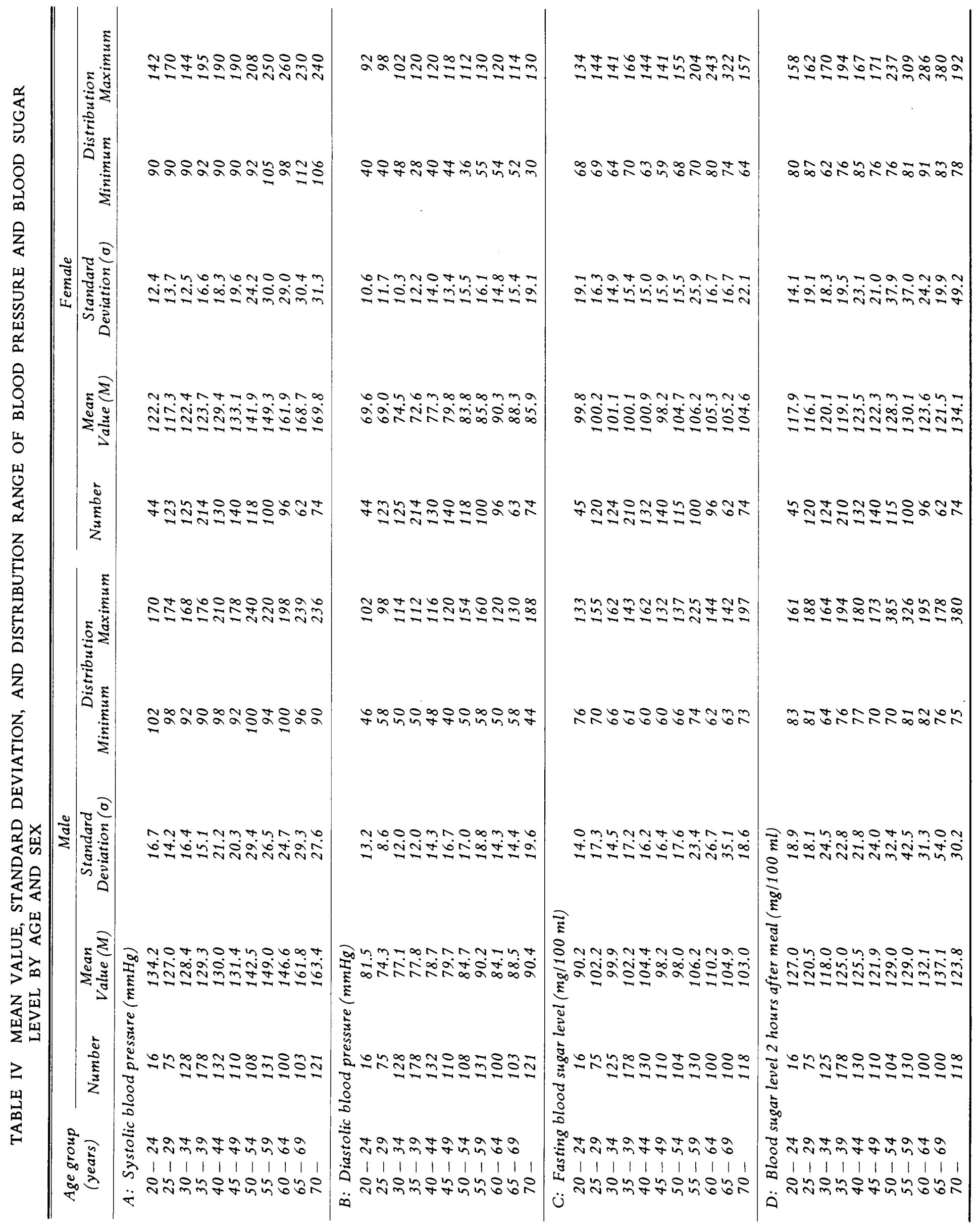

Japanese Circulation Journal Vol. 46, December 1982 
TABLE V CORRELATION $(r)$ BETWEEN TWO QUANTITATIVE CHARACTERS $(i, j)$ IN FAMILY GROUPS

\begin{tabular}{|c|c|c|c|c|c|c|c|c|}
\hline Pair of Two characters & \multicolumn{2}{|c|}{ Father } & \multicolumn{2}{|c|}{ Mother } & \multicolumn{2}{|c|}{ Son } & \multicolumn{2}{|c|}{ Daughter } \\
\hline$i \quad j$ & No. & $r$ & No. & $r$ & No. & $r$ & No. & $r$ \\
\hline Systolic BP-Diastolic BP & 531 & $0.740^{* *}$ & 683 & $0.727^{* *}$ & 668 & $0.546^{* *}$ & 546 & $0.512^{* *}$ \\
\hline Systolic BP - Fasting BS & 525 & $0.089 *$ & 665 & 0.006 & 660 & 0.048 & 535 & $0.090^{*}$ \\
\hline Systolic BP -2 hr BS & 507 & $0.105^{*}$ & 673 & 0.013 & 627 & $0.104^{*}$ & 521 & 0.026 \\
\hline Diastolic BP - Fasting BS & 522 & 0.018 & 665 & 0.029 & 659 & 0.055 & 534 & 0.075 \\
\hline Diastolic BP $-2 \mathrm{hr} B S$ & 504 & 0.057 & 673 & $0.081^{*}$ & 626 & $0.108^{*}$ & 519 & $0.101^{*}$ \\
\hline Fasting $B S-2 h r B S$ & 507 & $0.434^{*}$ & 669 & $0.441^{*}$ & 639 & $0.430^{*}$ & 519 & $0.429^{*}$ \\
\hline
\end{tabular}

$*=$ significant at $5 \%$ level, $\quad * *=$ significant at $1 \%$ level

TABLE VI CORRELATION $(\mathrm{r} F \cdot \mathrm{S}, \mathrm{r} M \cdot \mathrm{D})$ BETWEEN TWO QUANTITATIVE CHARACTERS IN PARENT-CHILD GROUPS

\begin{tabular}{|c|c|c|c|c|c|}
\hline \multicolumn{2}{|c|}{ Pair of two characters } & \multicolumn{2}{|c|}{ Father-Son group } & \multicolumn{2}{|c|}{ Mother-Daughter group } \\
\hline$i$ & $j$ & Number & ${ }^{r} F \cdot S$ & Number & $r_{M \cdot D}$ \\
\hline Systolic BP & - Systolic BP & 405 & 0.068 & 478 & $0.162^{* *}$ \\
\hline Systolic BP & - Diastolic BP & 404 & 0.015 & 478 & $0.135 * *$ \\
\hline Systolic BP & - Fasting BS & 415 & 0.002 & 481 & 0.078 \\
\hline Systolic BP & $-2 h r B S$ & 385 & 0.066 & 460 & 0.011 \\
\hline Diastolic BP & - Systolic BP & 403 & 0.045 & 478 & $0.162^{* *}$ \\
\hline Diastolic BP & - Diastolic BP & 402 & 0.069 & 478 & $0.224^{* *}$ \\
\hline Diastolic BP & $-2 h r B S$ & 383 & 0.083 & 460 & 0.060 \\
\hline Fasting BS & - Systolic BP & 408 & 0.053 & 468 & 0.025 \\
\hline Fasting BS & - Diastolic BP & 407 & 0.070 & 468 & 0.077 \\
\hline Fasting $B S$ & - Fasting BS & 420 & $0.257^{* *}$ & 474 & $0.298^{* *}$ \\
\hline Fasting $B S$ & $-2 h r B S$ & 389 & $0.218^{* *}$ & 451 & $0.255^{* *}$ \\
\hline $2 h r B S$ & - Systolic BP & 393 & 0.066 & 476 & 0.025 \\
\hline $2 h r B S$ & - Diastolic BP & 392 & 0.044 & 476 & $0.111^{*}$ \\
\hline $2 h r B S$ & - Fasting BS & 403 & $0.186^{* *}$ & 479 & $0.229 * *$ \\
\hline $2 h r B S$ & $-2 h r B S$ & 375 & $0.195^{* *}$ & 458 & $0.304^{* *}$ \\
\hline
\end{tabular}

$*=$ significant at $5 \%$ level, $* *=$ significant at $1 \%$ level

TABLE VII HERITABILITY $\left(h^{2}\right)$ OF BLOOD PRESSURE AND BLOOD SUGAR LEVEL

\begin{tabular}{cccccc}
\hline \hline \multirow{2}{*}{ Quantitative characters } & \multicolumn{2}{c}{ Father-Son group } & & \multicolumn{2}{c}{ Mother-Daughter group } \\
\cline { 2 - 3 } & Number & $h^{2} \pm S E$ & & Number & $h^{2} \pm S E$ \\
\hline Systolic BP & 405 & $0.136 \pm 0.099$ & & 478 & $0.324 \pm 0.089$ \\
Diastolic BP & 402 & $0.138 \pm 0.099$ & & 478 & $0.448 \pm 0.087$ \\
Fasting BS & 420 & $0.514 \pm 0.091$ & & 474 & $0.596 \pm 0.083$ \\
2 hr BS & 375 & $0.390 \pm 0.099$ & & 458 & $0.608 \pm 0.085$ \\
\hline
\end{tabular}

\section{DISCUSSION}

Since quantitative characters such as $\mathrm{BP}$ and BS in this report usually undergo a change in values according to the individual's sex, age and environmetal conditions, the analy tical errors are inevitable when their actually observed vaules are used for the genetic analyses even if they have been obtained from a relatively homogeneous population. The co-ordinate transformation of Japanese Circulation Journal Vol. 46, December 1982 
TABLE VIII PHENOTYPIC, GENOTYPIC AND ENVIRONMENTAL CORRELATIONS BETWEEN TWO CHARACTERS $(i, j)$ IN PARENT-CHILD GROUPS

\begin{tabular}{|c|c|c|c|c|c|c|}
\hline Pair of two characters & \multicolumn{2}{|c|}{ Phenotypic $\left(r_{P i j}\right)$} & \multicolumn{2}{|c|}{ Genotypic $\left(r_{G i j}\right)$} & \multicolumn{2}{|c|}{ Environmental $\left(r_{E i j}\right)$} \\
\hline$j$ & $\begin{array}{l}\text { Father- } \\
\text { Son }\end{array}$ & $\begin{array}{l}\text { Mother- } \\
\text { Daughter }\end{array}$ & $\begin{array}{l}\text { Father- } \\
\text { Son }\end{array}$ & $\begin{array}{l}\text { Mother- } \\
\text { Daughter }\end{array}$ & $\begin{array}{l}\text { Father- } \\
\text { Son }\end{array}$ & $\begin{array}{l}\text { Mother- } \\
\text { Daughter }\end{array}$ \\
\hline Systolic BP - Diastolic BP & $\begin{array}{r}0.63 * \\
\pm 0.003\end{array}$ & $\begin{array}{r}0.61 * * \\
\pm 0.017\end{array}$ & $\begin{array}{r}0.37 * \\
\pm 0.043\end{array}$ & $\begin{array}{r}0.77 * \\
\pm 0.018\end{array}$ & $\begin{array}{r}0.677 \\
\pm 0.027\end{array}$ & $\begin{array}{r}0.5 * * \\
\pm 0.034\end{array}$ \\
\hline Systolic BP - Fasting BS & $\begin{array}{r}0.064 \\
\pm 0.099\end{array}$ & $\begin{array}{r}0.023 \\
\pm 0.046\end{array}$ & $\begin{array}{r}0.078 \\
\pm 0.049\end{array}$ & $\begin{array}{r}0.201 \\
\pm 0.044\end{array}$ & $\begin{array}{r}0.068 \\
\pm 0.049\end{array}$ & $\begin{array}{r}-0.12 * \\
\pm 0.045\end{array}$ \\
\hline Systolic BP $-2 \mathrm{hr} B S$ & $\begin{array}{r}0.104 \\
\pm 0.050\end{array}$ & $\begin{array}{r}0.018 \\
\pm 0.047\end{array}$ & $\begin{array}{r}0.573 \\
\pm 0.034\end{array}$ & $\begin{array}{r}0.075 \\
\pm 0.046\end{array}$ & $\begin{array}{l}-0.039 \\
\pm 0.051\end{array}$ & $\begin{array}{r}-0.029 \\
\pm 0.047\end{array}$ \\
\hline Diastolic BP - Fasting BS & $\begin{array}{r}0.031 \\
\pm 0.049\end{array}$ & $\begin{array}{r}0.047 \\
\pm 0.045\end{array}$ & $\begin{array}{r}0.53 * \\
\pm 0.035\end{array}$ & $\begin{array}{r}0.39 * \\
\pm 0.038\end{array}$ & $\begin{array}{r}\quad * * \\
-0.173 \\
\pm 0.048\end{array}$ & $\begin{array}{r}-0.337 \\
\pm 0.040\end{array}$ \\
\hline Diastolic $B P-2 \mathrm{hr} B S$ & $\begin{array}{r}0.078 \\
\pm 0.051\end{array}$ & $\begin{array}{r}0.090 \\
\pm 0.046\end{array}$ & $\begin{array}{r}0.521 \\
\pm 0.037\end{array}$ & $\begin{array}{r}0.313 \\
\pm 0.042\end{array}$ & $\begin{array}{r}-0.059 \\
\pm 0.051\end{array}$ & $\begin{array}{r}-0.15 * \\
\pm 0.045\end{array}$ \\
\hline Fasting BS -2 hr BS & $\begin{array}{r}0.432 \\
\pm 0.041\end{array}$ & $\begin{array}{r}0.43 * \\
\pm 0.038\end{array}$ & $\begin{array}{r}0.89 * \\
\pm 0.010\end{array}$ & $\begin{array}{r}0.803 \\
\pm 0.017\end{array}$ & $\begin{array}{r}0.053 \\
\pm 0.051\end{array}$ & $\begin{array}{l}-0.088 \\
\pm 0.047\end{array}$ \\
\hline
\end{tabular}

$*=$ significant at $5 \%$ level, $\quad * *=$ significant at $1 \%$ level

TABLE IX COMPLICATION FREQUENCY OF HYPERTENSION AND DIABETES MELLITUS IN AGE GROUP

\begin{tabular}{|c|c|c|c|c|c|c|}
\hline \multirow{2}{*}{$\begin{array}{c}\text { Age group } \\
\text { (years) }\end{array}$} & \multicolumn{6}{|c|}{ Components in the Equation ${ }^{a}$ ) } \\
\hline & $X Y$ & $x$ & $y$ & $x \cdot y$ & $\Delta$ & $\Delta / x \cdot y$ \\
\hline \multirow{3}{*}{$31-50$} & \multirow{3}{*}{$0.29^{\mathrm{b})}$} & \multirow{3}{*}{$\left.0.1363^{\mathrm{d}}\right)$} & $0.0256^{\mathrm{e})}$ & 0.0035 & +0.2865 & 82.86 \\
\hline & & & $\left.0.0294^{\mathrm{f}}\right)$ & 0.0040 & +0.2860 & 72.50 \\
\hline & & & $0.0556^{\mathrm{f})}$ & 0.0076 & +0.2824 & 38.16 \\
\hline \multirow{3}{*}{$41-60$} & \multirow{3}{*}{$0.386^{\mathrm{c})}$} & \multirow{3}{*}{$0.2781^{\mathrm{d})}$} & $\left.0.0448^{\mathrm{e}}\right)$ & 0.0125 & +0.3755 & 30.88 \\
\hline & & & $0.0377^{\mathrm{f})}$ & 0.0105 & +0.3755 & 36.76 \\
\hline & & & $0.0695^{\mathrm{f})}$ & 0.0193 & +0.3667 & 20.00 \\
\hline
\end{tabular}

\footnotetext{
a) See the text for the equation and the definitions of each figure.

b) Data quoted from the DATA II in Table I.

c) Data quoted from the DATA I in Table I.

d) Mean value of the frequencies of hypertension $(150 \mathrm{mmHg}$ or over of systolic BP) calculated from data in Table II.

e) Values calculated from the DATA I in Table III.

f) Values calculated from the DATA II in Table III.
}

an actual data performed in this report may be a very effective statistical method to overcome the essential analytical errors mentioned above. The sex- and the age-dependent differencies of each actual data may be corrected by co-ordinate transformation of the data. The other advantage of performing co-ordinate transformation is that all the actual data collected in a relatively small population can be used for the genetic analyses.

BP and BS have been considered to be highly inheritable characters in humans. Oshiro ${ }^{7}$ has estimated the heritability of essential hyperten- sion to be 0.48 on the basis of systolic BP. Mimura ${ }^{8}$ has estimated heritability of fasting BS as 0.536 and that of $2 \mathrm{hr}$ BS as 0.610 . The heritabilities of systolic BP in the present report, $0.136 \pm 0.099$ in the father-son group and $0.324 \pm 0.089$ in the mother-daughter group (Table VII), were much lower in values than those of Oshiro? While the heritabilities of BS in the present report, $0.514 \pm 0.091$ for fasting BS and $0.390 \pm 0.099$ for $2 \mathrm{hr}$ BS in the fatherson group and $0.596 \pm 0.083$ for fasting BS and $0.608 \pm 0.085$ for $2 \mathrm{hr}$ BS in the mother-daughter 
group (Table VII), were similar to those of Mimura? These results regarding the heritabilities of BP and BS suggest that genetic and environmental factors may play some important roles in the manifestation of hypertension and diabetes mellitus.

It is not rare that a certain genetic correlation is observed between two or more quantitative characters of an individual. This genetic correlation may be observed as the manifestation of those characters having some relations with each other. This is mainly attributable to the following two factors: 1) the genetic factors which are involved in common groups of genes and 2) the common environmental factors. The genetic factors can be further divided into 1) the multiple effect in which the same gene or group of genes is involved in the manifestation of the two or more characters and 2) the linkage effect in which there are two different genes or group of genes with a linkage between them with a result of the behaviors of just like a single gene or common group of genes. A correlation due to genetic factors is called the genetic correlation and that due to environmental factors the environmental correlation.

Regarding the genetic correlation of BP and BS, it was observed that the genotypic correlation gave higher coefficient values than did the phenotyic correlation and most of genotypic correlations gave statistically significant correlation coefficients (Table VIII). These results suggest that hypertension and diabetes mellitus are genetically correlated.

Accordingly, if the genotypic correlation $\left(\mathrm{r}_{\mathrm{G} i j}\right)$ is $\mathrm{r}_{\mathrm{G} i j} \cong 1$, it indicates that the two quantitative characters $(i, j)$ are controlled by the same polygenic system, and then if $\mathrm{r}_{\mathrm{G} i j} \cong 0$, it indicates that the $i$ and $j$ are controlled by two different independent polygenic systems, and lastly if $\mathrm{r}_{\mathrm{G} i j}$ is between 0 and 1 , it implies the multiple effect of several polygenic systems. Since the $\mathrm{r}_{\mathrm{G} i j}$ of BP and BS in this report were proved to be 0.075 to 0.573 with a mean value of 0.337 (Table VIII), it may be suggested that the polygenic systems controlling the two quantitative characters are partially overlapped and have the multiple effect on the manifestations of these two quantitative characters. Therefore, it is suspected that there may be some common genetic causes for the development of hypertension and diabetes mellitus.

On the other hand, the environmental correlation ( $\mathrm{r}_{\mathrm{E} i j}$ ) of BP and BS were proved to be 0.029 to 0.337 with a mean value of 0.164 and to be mostly negative in sign (Table VIII). These results suggest that the two quantitative characters are environmentally correlated to a certain extent and are inversely correlated each other. These findings may have a great significance both genetically and clinically. Namely, the lower environmental correlations of BP and BS may be attributed to some environmental improvements to prevent the developments of hypertension and diabetes mellitus. Thus, the inversely correlated environmental factors mean that the enviromental factors which lower BP may elevate BS, and vice versa. In this context, it is necessary to consider drugs as one of the environmental factors. Thiadizes, the most frequently used anti-hypertensive diuretics, has been recently found to induce an abnormal glucose tolerance on patients. This side effect may be explained by the inverse environmental correlation between BP and BS. However, it is not likely that every anti-hypertensive drug other than thiazides always induces an abnormal glucose tolerance. In addition, the environmental factors constitute a variety of factors other than drugs, such that the matter is very complicated. Therefore, further investigations on the environmental factors of BP and BS are needed.

As initially stated in this report, the correlation between hypertension and diabetes mellitus has been suspected for a long time on the basis of the relatively high incidence of their complications. To elucidate whether or not hypertension is invariably complicated with diabetes mellitus in an unusually high frequency, and vice versa, the genetic analyses should be carried out on the data collected in relatively large random populations. Furthermore, the age-dependent effects on the incidences of the two diseases should be taken into account at such genetic analyses, because the incidence of the two diseases may increase with age.

We estimated the complication frequency $(\Delta)$ of hypertension and diabetes mellitus with the published age-dependent data listed in Tables I, II and III. Accordingly, if hypertension and diabetes mellitus are due to entirely different causes, $\Delta \cong 0$ will be obtained because the complication incidence of hypertension - diabetes mellitus should be equal to each individual incidence of the two diseases; and if the two diseases are due to partially identical causes or due to correlated ones, $\Delta>0$ will be obtained. Since the $\Delta$ of positive and the values of 20.00 to 
82.86 with a mean value of 46.86 for the $\Delta / x \cdot y$ (the $\Delta$ divided by the incidence of hypertension times the incidence of diabetes mellitus) were obtained (Table IX), it evidently indicate that hypertension and diabetes mellitus are not the two entirely independent diseases. These results may suggest that the two diseases share some causal factors or have at least some correlations in the developmental bases of the two diseases.

As shown in the distribution range in Table IV, each minimum value of systolic BP, diastolic BP, fasting BS and $2 \mathrm{hr}$ BS did not vary greatly according to age, suggesting no age-dependent effects on the minimum values. While their maximum values increased with age, implying that the variance of the individual values expands with age, shifting the maximum values upwards. This is an important genetic finding. Because the genetic analyses based on more detailed ageclassified data would lead to a further elucidation of the age-dependent changes of phenotypic, genotypic, and environmental correlations of BP and BS. These types of genetic analyses give more of clinically important information. Such analyses, however, were impossible in the present studies because of a shortage of samples. They remain to be investigated in the future.

It should also be investigated in some future studies whether partly poly-genetic and chiefly monogenetic factors as well as a chromosomal aberration possibly play some role at both ends of the distribution of BP and BS in a population.

The genetic relation between hypertension and diabetes mellitus must be investigated not only from the point of view of BP and BS but also from a wider perspective including various other diseases. Investigations of inter-disease genetic relationships make important contributions to therapeutic and preventive medicine in addition to their contributions to the explanations of causes and of the interrelationships of the diseases investigated.

\section{Acknowledgement}

The authors are pleased to acknowledge the assistance of Dr. Shigeyuki Tsunenari, Department of Legal Medicine, Kumamoto University Medical School, in preparing this manuscript.

\section{REFERENCES}

1. MIMURA G: Clinic of thiazaid diabetes. Diabetes 14: 17, 1971 (in Japanese)

2. MIMURA G: Hypertension and diabetes. Geriatric Med 9: 184, 1971 (in Japanese)

3. MIMURA G: Diabetes mellitus and cerebrovascular disease. In Diabetes Mellitus, ed by MIYAO S, MIMURA G, Ashia Shobo, Tokyo, 1974, p 127 (in Japanese)

4. The Japanese Ministry of Health and Welfare: Kokumin Eiyo no Genjyo. Tokyo, 1970 (in Japanese)

5. KOBAYASHI Y: The incidence and early therapy of diabetes mellitus in Japan. Medicine of Japan in 1956, Vol 1, p 641 (in Japanese)

6. KOBAYASHI Y: Several problems in general examination of diabetes mellitus. Medicine of Japan in 1963, Vol 4, p 301 (in Japanese)

7. OSHIRO S: Heredity of essential hypertension. Bull Inst Const Med Kumamoto Univ 14: 225, 1964 (in Japanese)

8. MIMURA G: Heredity and factor of diabetes mellitus. Japanese Medicine of 1967, Vol 3, p 114 (in Japanese) 